\title{
Predicting Alcohol Pre-Drinking in Australian Undergraduate Students Using an Integrated Theoretical Model
}

\section{Abstract}

2 Background: The aim of the present study was to examine the social-cognitive and

3 motivational factors associated with pre-drinking based on a model integrating motivational

4 constructs from self-determination theory and belief-based constructs from the theory of

5 planned behaviour.

6 Methods: A prospective correlational design was used. Participants $(N=286 ; 66.4 \%$ female $)$

7 completed self-report measures of past alcohol consumption, autonomous and controlled

8 forms of motivation from self-determination theory, and attitudes, subjective norms,

9 perceived behavioural control, and behavioural intentions from the theory of planned

10 behaviour at baseline. Participants reported pre-drinking frequency four weeks later.

11 Results: Variance-based structural equation modeling showed that the hypothesized model

12 predicted $54 \%$ of the variance in pre-drinking intentions at baseline, and $20 \%$ of the variance

13 in pre-drinking behaviour at follow-up. Mediation analyses indicated strong, statistically-

14 significant effects of autonomous motivation on intentions to pre-drink, partially mediated by

15 attitudes and subjective norms. Intention and perceived behavioural control significantly

16 predicted pre-drinking frequency.

17 Conclusions: Results provide support for the hypothesized model relationships. Autonomous

18 motivation, attitude, subjective norm, and perceived behavioural control were influential in

19 forming students' intentions to pre-drink. However, consistent with previous findings, the

20 intention-behaviour relationship was relatively weak. Future research should look to non-

21 intentional and volitional processes that may influence pre-drinking in undergraduates.

22 Keywords: pre-drinking; pre-loading; alcohol consumption; theory of planned behaviour;

23 self-determination theory; undergraduate alcohol consumption 
Pre-drinking is a pattern of alcohol consumption that has received increased intention in research on the harmful effects of alcohol. Pre-drinking (also referred to as, pre-loading, pre-partying, pre-gaming) is defined as the consumption of alcohol, usually at one's home or another's residence, prior to attending another social event which usually involves further alcohol consumption (e.g., attending bars, clubs; Pedersen \& LaBrie, 2007). Research by DeJong et al. (2010) showed students reported consuming, on average, 4.9 drinks during their most recent pre-drinking occasion. This average exceeds safe drinking guidelines that recommend consuming fewer than four standard drinks on drinking occasions to avoid the risks of alcohol-related harm (National Health and Medical Research Council, 2009). Recent research indicates that university student pre-drinkers report higher total alcohol intake on drinking occasions that involve pre-drinking, and are more likely to be involved in alcoholrelated accidents and violence, than on occasions that do not involve pre-drinking (Hummer, Napper, Ehret, \& LaBrie, 2013). A recent Australian study has demonstrated that three quarters of drinkers between the ages of 18 and 25 report pre-drinking within the past year (MacLean \& Callinan, 2013). Given the majority of Australian university students fall within this age bracket and are known to report higher incidence of risky drinking practices when compared to their non-student peers (Hallett et al., 2012; Kypri, Cronin, \& Wright, 2005), pre-drinking is likely a prevalent practice among Australian university students.

Recent studies have looked to the psychological, social, and economic factors related to the increasing prevalence of pre-drinking as a pattern of alcohol consumption. A major reason for pre-drinking appears to be the lower cost of consuming pre-purchased alcohol, when compared with purchasing and consuming alcohol at licensed venues (Caudwell \& Hagger, 2014; MacLean \& Callinan, 2013; Miller \& Droste, 2013). Pre-drinking is also considered to have emerged in response to increased legislative or premise-based policies intended to reduce excessive drinking at licensed venues effectively displacing excessive 
1 drinkers to private residences (Wells, Graham, \& Purcell, 2009; Wiggers, Tindall, Gillham, \&

2 Lecathelinais, 2012). The social elements of pre-drinking have also been linked to its

3 prevalence. University students report pre-drinking as an opportunity to socialize, relax, and

4 become sufficiently intoxicated prior to attending the main event (Wells et al., 2009).

5 Interpersonal enhancement (drinking for enjoyment or entertainment) also appears a strong

6 motive underlying student pre-drinkers (Caudwell \& Hagger, 2014; LaBrie, Hummer,

7 Pedersen, Lac, \& Chithambo, 2012).

There have been relatively few applications of psychological theory to understand pre-drinking behaviour (see Foster \& Ferguson, 2013). Theory-based research is important because it provides a hypothesis-testing framework for understanding the mechanisms and processes underlying health behaviours, and paves the way for guiding the development of effective interventions that target the theoretical constructs that have been found to predict health-related behaviour, such as reducing alcohol consumption. The theory of planned behaviour (Ajzen, 1991) is at theoretical framework that has been widely used in the health behaviour field (Ajzen, 2014; McEachan, Conner, Taylor, \& Lawton, 2011). The theory posits that behavioural intention is the proximal predictor of subsequent behaviour, and that intention is predicted by three variables; attitude, subjective norm, and perceived behavioural control (Ajzen, 1991). Attitude reflects an individual's beliefs that performing a given 'target' behaviour will lead to salient outcomes; subjective norm reflects the extent to which an individual believes that important social referents want them to engage in the target behaviour; and perceived behavioural control reflects the extent of an individual's capacity to engage in the target behaviour. Intention mediates the effect of these constructs on behaviour, with perceived behavioural control also exerting a direct effect when it approximates actual behavioural control (Ajzen, 1991). 
2 health behaviours and contexts (Armitage \& Conner, 2001; Hagger, Chatzisarantis, et al.,

3 2007; McEachan et al., 2011). A recent meta-analysis of studies adopting the theory in the

4 context of alcohol consumption found support for the relationships posited by the theory,

5 between attitudes and intentions, and intention and behaviour (Cooke, Dahdah, Norman, \&

6 French, 2014). However, these relationships differed depending on the type of alcohol

7 consumption behaviour under investigation, with authors noting a paucity of investigating

8 certain patterns of alcohol consumption, such as pre-drinking (Cooke et al., 2014). Further,

9 augmentations of the theory of planned behavior that may increase the variance explained for

10 certain behaviours should be considered (Conner, 2014; McEachan et al., 2011). Therefore,

11 alternative theoretical approaches that may increase predictive efficacy of existing health

12 behavioural models, that offer insight into the elements underlying behavioural intention and

13 engagement and may hold utility in designing health behavioural interventions, should be

14 considered (Conner, 2014; Hagger, 2009; Hagger \& Chatzisarantis, 2009b).

Another theory that has been applied extensively to understand and predict health

behaviour is self-determination theory (Deci \& Ryan, 1985). The key premise of self-

determination theory is that the quality of an individual's motivation is an important factor determining behavioural engagement and persistence. Motivation is posited to exist on a continuum reflecting the perceived origins of behavioural engagement. The continuum ranges from controlled motivation to autonomous orientation and is known as the perceived locus of causality (Ryan \& Connell, 1989). External regulation denotes motivation from external sources, such as to gain reward or to avoid punishment, or from others. Introjected regulation refers to individuals being motivated to pursue certain behaviours to avoid feelings such as guilt or shame. Both external regulation and introjected regulation are considered types of controlled motivation. Identified regulation relates to goals, or favored outcomes (e.g., pre- 
1 drinking to save money, or because it makes for an enjoyable occasion). Intrinsic motivation

2 reflects engaging in behaviour for reasons consistent with an individual's personal goals and

3 needs, in the absence of any external contingency, and done for the inherent enjoyment and

4 satisfaction the behaviour offers. Identified regulation and intrinsic motivation are considered

5 autonomous forms of motivation. An additional element to self-determination theory is that

6 motives are proposed to arise from the satisfaction of basic psychological needs that are

7 considered innate and universal. Specifically, individuals are more likely to experience

8 autonomous forms of motivation toward behaviour when three psychological needs

9 (autonomy, competence, and relatedness) are met (Ryan \& Deci, 2000). Conversely, when an

10 individual feels these needs are not supported, or thwarted, they experience less self-

11 determined forms of motivation. Research has demonstrated that the fulfilment of these psychological needs are linked to greater reported autonomous motivation and higher levels of engagement in various health-promoting behaviours (Ng et al., 2012; Ryan \& Deci, 2000).

14 Meta-analyses of research adopting self-determination theory have found it a sound conceptual framework for assessing the influence of motivation on a range of health-related behaviours (N. L. D. Chatzisarantis, Hagger, Biddle, Smith, \& Wang, 2003; Ng et al., 2012).

A recent approach has been to integrate self-determination theory and the theory of planned behaviour to improve model predictive efficacy and give further insight into the motivational elements underlying health behaviour (Hagger \& Chatzisarantis, 2009b). Integrating compatible theories can address individual shortcomings in each theory and give a more comprehensive account of the factors associated with health behaviours which may influence further research, policy, and potential for theory-based interventions (Hagger, 2009). Integration of self-determination theory and the theory of planned behaviour is based on the notion that an individual's autonomous and controlled motivational orientation from self-determination theory influences the formation of intention, through the mediation of 
1 attitudes, subjective norm, and perceived behavioural control, from the theory of planned

2 behaviour (Hagger \& Chatzisarantis, 2009). It is important to note the differing ontological

3 and epistemological perspectives of these two theories and whether they could potentially

4 offer complementary explanations of behaviour. Self-determination theory comes from an

5 organismic perspective, based on the fulfilment of psychological needs; as such, motivational

6 orientations reflect generalised tendencies to act in a behavioural domain in order to fulfil

7 these needs. In contrast, social cognitive theories such as the theory of planned behaviour are

8 based on beliefs regarding future engagement in an activity. A possible means by which these

9 theories could complement each other lies in explanations of origins and how distal motives

10 are translated into actions. Self-determination theory provides some indication of the origins

11 of the social cognitive beliefs, based on the idea that an individual will seek out further opportunities to engage in behaviours that are need-satisfying, and form congruent beliefs regarding these behaviours. The theory of planned behaviour assists in delineating the process by which the generalised motives from self-determination theory are converted into actual behaviour. For example, an individual who feels autonomously motivated to pre-drink may form congruent beliefs regarding the evaluation of future engagement in pre-drinking; these beliefs may in turn influence their intentions to pre-drink.

Research has adopted the integration of the two theories to predict behaviour (Hagger \& Chatzisarantis, 2009b, 2012). In the context of alcohol consumption, the integrated model has been adopted to heavy episodic drinking in a sample of company employees across three time points (Hagger, Lonsdale, Hein, et al., 2012). Results indicated that, identified regulation, an autonomous form of motivation, and attitudes to reduce excessive drinking, accounted for a substantial proportion of the variance in heavy episodic drinking behaviour, suggesting that participants may choose to reduce their alcohol consumption because they 
1 value the benefits of avoiding adverse alcohol-related health effects and believe it beneficial

2 to keep their drinking within safe limits.

\section{The present study}

Given the evidence supporting the integration of self-determination theory and the

5 theory of planned behaviour into a single model (Hagger \& Chatzisarantis, 2009b; Hagger,

6 Lonsdale, Hein, et al., 2012), it may provide a theoretical framework to guide research into

7 the motives underpinning pre-drinking behaviour. Research on self-determination theory has

8 tended to focus on links between autonomous motivation and avoidance of risky, health-

9 compromising behaviours (e.g., alcohol consumption, eating a high-fat diet), and between

10 autonomous motivation and uptake of adaptive health behaviours ( $\mathrm{Ng}$ et al., 2012). Much of

11 the research investigating the link between self-determination theory and alcohol consumption have found controlled forms of motivation tend to be associated with increased alcohol consumption, and conversely, autonomous forms of motivation are associated with avoidance of, or reduced alcohol consumption (Neighbors, Lewis, Fossos, Grossbard, \& Brown, 2007). Generally, research suggests that controlled motivation leads individuals to consume alcohol due to social pressures, typical of exhibiting extrinsic rationales for behavioural engagement (Chawla, Neighbors, Logan, Lewis, \& Fossos, 2009; Neighbors, Larimer, Markman G., \& Knee, 2004). However, Amiot, Sansfaçon, and Louis (2013) comment on the lack of self-determination theory research on the relationship between autonomous motivation and engaging in harmful behaviours (e.g., drug use, cheating). They found that when considering harmful behaviours, university students favoring in-group norms reported higher self-determined motivation to engage in behaviour consistent with the norms.

23 This indicates that individuals may be similarly autonomously motivated to pursue health24 risk behaviours (e.g., pre-drinking), in part due to normative influences. Therefore, the 25 influence of subjective norm in the theory of planned behaviour may be congruent with 
1 controlled or autonomous reasons for acting. In addition to these studies, the meta-analysis by

2 McEachan et al. (2011) included studies adopting the theory of planned behaviour on

3 intention to avoid alcohol consumption as well as to consume alcohol, which show

4 comparable predictive efficacy in terms of the theoretical components. Considering these

5 findings, we adopted a novel approach in the present study to apply the integrated model to

6 predict intentions to pre-drink and pre-drinking frequency in undergraduate students.

We proposed a series of hypotheses that reflected the stimulated pattern of effects of

8 the integrated model, based upon the proposed motivational sequence in which relations

9 between motivational orientations from self-determination theory and intentions with respect

to pre-drinking are mediated by constructs from the theory of planned behaviour (see Figure

111 for a diagrammatic representation of the proposed relationships between theoretical

12 constructs). Specifically, we hypothesized that autonomous motivation toward pre-drinking

13 would positively predict attitude, subjective norm, and perceived behavioural control $\left(\mathrm{H}_{1}\right)$.

14 This hypothesis was based on previous research finding attitudes and perceived behavioural control are more likely consistent with autonomous motivation (e.g., Hagger, Chatzisarantis, \& Biddle, 2002; Hagger, Chatzisarantis, \& Harris, 2006b; Hagger, Lonsdale, Hein, et al., 2012) and that individuals may also be autonomously motivated to engage in behaviour because drinking at the behest of others is consistent with their autonomous motives and their genuine sense of self (Amiot et al., 2013). However, we also expected that controlled motivation would predict subjective norm $\left(\mathrm{H}_{2}\right)$ as this variable may reflect perceived social approval to engage in behaviour, consistent with externally-referenced reasons for acting and previous research regarding controlled orientations and alcohol consumption (Chawla et al., 2009; Knee \& Neighbors, 2002). Consistent with the latter proposal, we expected no effects

24 for controlled motivation on attitudes and perceived behavioural control $\left(\mathrm{H}_{3}\right)$ as these are more likely to be aligned with autonomous motivation and have been consistently related to 
1 beliefs that reflect this motive (i.e., attitudes and perceived behavioural control). In keeping

2 with the main tenets of the theory of planned behaviour (Ajzen, 1991), we expected attitude,

3 subjective norm, and perceived behavioural control to significantly predict intention $\left(\mathrm{H}_{4}\right)$. We

4 also hypothesized that intention and perceived behavioural control $\left(\mathrm{H}_{5}\right)$ would predict pre-

5 drinking frequency directly, where the latter approximated actual control (i.e., where

6 perceptions of control reflect actual behavioural control unrelated to one's intentions). With

7 regards to the motivational sequence specified by the integrated model, and results of

8 previous research (Amiot et al., 2013; Hagger, Lonsdale, Hein, et al., 2012), we expected the

9 effects of autonomous motivation on intention be mediated by attitude, subjective norm, and

10 perceived behavioural control $\left(\mathrm{H}_{6}\right)$. Similarly, we expected the effect of controlled motivation

11 on intention to be mediated by subjective norm only $\left(\mathrm{H}_{7}\right)$ and that there would be no

12 mediation of this path by attitude or perceived behaviour control $\left(\mathrm{H}_{8}\right)$. Further, we anticipated

13 the direct effects of autonomous and controlled motivation on intention would be zero, as the

14 effects would be fully mediated by the proximal antecedent constructs from the theory of

15 planned behaviour $\left(\mathrm{H}_{9}\right)$. Finally, we hypothesized three-segment paths from autonomous

16 motivation to pre-drinking behaviour through attitude, subjective norm, perceived

17 behavioural control, respectively, and intention $\left(\mathrm{H}_{10}\right)$. We also proposed that autonomous

18 motivation would predict pre-drinking behaviour indirectly through perceived behavioural

19 control $\left(\mathrm{H}_{11}\right)$. Similarly, we hypothesized a three-segment path from controlled motivation to

20 pre-drinking behaviour through subjective norm and intention $\left(\mathrm{H}_{12}\right)$, but not through attitude

21 nor perceived behavioural control and intention, or through perceived behavioural control

$22\left(\mathrm{H}_{13}\right)$.

\section{Method}

\section{Design}


A prospective correlational design was adopted. Study measures were included in two separate internet-based questionnaires administered at two time points, four-weeks apart. of planned behaviour as well as a self-report measure of past alcohol consumption were collected at baseline, with behavioural data (i.e., pre-drinking sessions) collected at a followup time point, four weeks later. Data were collected over a period of four months ${ }^{1}$.

\section{$7 \quad$ Participants}

Ethical approval was secured by the [University omitted for masked review]

university human research ethics committee prior to data collection. Undergraduate students

were recruited via social media and recruitment posters placed on noticeboards and

Western Australian university. A total of 508 participants completed the baseline questionnaire with $341(67.1 \%)$ completing the follow-up questionnaire. $^{2}$

\section{Measures}

Past Alcohol Consumption Behaviour. Participants' alcohol consumption was 2003). Participants were asked to enter the amount of alcohol they had consumed in each

\footnotetext{
${ }^{1}$ We conducted a univariate ANOVA to test whether self-reported pre-drinking frequency (recorded at followup) differed significantly between months of data collection. The result was statistically non-significant; $F$ $(3,278)=.529, p=.663$; partial $\eta^{2}=.006$, indicating a lack of sampling bias.

${ }^{2}$ A MANOVA indicated there was no significant difference between completers and non-completers on theoretical and behavioural measures at baseline; $F(36,456)=.894, p=.648$; Wilk's $\Lambda=0.934$, partial $\eta^{2}=$ .066 . Tests of attrition bias revealed no statistically-significant difference in age $(t(498)=-3.73, p=.709)$ or gender distribution $\left(\chi^{2}(1)=.046, p=.830\right)$ across completers and non-completers who provided useable responses.
} 
1 week in standard drink equivalents over the previous four weeks. In order to mitigate social

2 desirability effects, we included statements reaffirming confidentiality as a preface to survey

3 questions, and provided participants with a pictorial reference to assist in estimating their

4 alcohol consumption, adapted from the National Health and Medical Research Council's

5 (2009) standard drinks guide.

\section{Definition of Pre-Drinking and Participant Identification as a Pre-Drinker.}

Participants were presented with the following statement defining pre-drinking behaviour, based on a conceptual definition provided by Pedersen and LaBrie (2007): “...drinking alcohol (purchased at a liquor store or supermarket) at your home or someone else's house before you 'go out' for the night (e.g., visiting a bar, pub, nightclub, music venue, gig, or other social gathering)" (p. 238). This definition has been frequently used in other predrinking research (e.g., Zamboanga, Schwartz, Ham, Borsari, \& Van Tyne, 2010).

Participants who indicated having engaged in pre-drinking in the past six months continued with the questionnaire and were invited to complete the follow-up upon completion, while those who had not were directed to an exit page.

Autonomous and Controlled Forms of Motivation. Measures of autonomous and controlled forms of motivation from self-determination theory were based on Ryan and Connell's (1989) perceived locus of causality scale and adapted from Hagger et al. (2011) to refer to pre-drinking behaviour. Participants were asked "Why are you likely to drink alcohol at your home or someone else's before 'going out'?" and were directed to respond to a series of reasons reflecting underlying motivational constructs: introjected regulation (e.g., "I feel ashamed when I do not drink before I go out"); extrinsic regulation (e.g., "I drink alcohol because other people say I should"); identified regulation (e.g., "It is important for me to drink alcohol before I go out"), and; intrinsic motivation (e.g., "I enjoy drinking before I go out"). Four items were used for each construct; with Likert-type response scales ranging from 
11 (not true at all) to 4 (very true). We used responses to introjected regulation and extrinsic

2 regulation items to create a scale for controlled motivation, and responses on identified

3 regulation and intrinsic motivation to create a scale for autonomous motivation.

Theory of Planned Behaviour. Items measuring the attitude, subjective norm, perceived behavioural control, and intention constructs from the theory of planned behaviour were developed in line with Ajzen's (2002) recommendations. Items made reference to the target behaviour (i.e., pre-drinking), the time frame of interest (i.e., over the past/next four weeks), and the behavioural context (i.e., on each individual occasion or session). Attitude was measured on five items preceded by a common stem: "For me, [pre-drinking] over the next four weeks is..." followed by five-point bipolar adjective scales: unimportant/important, not worthwhile-worthwhile, harmful-beneficial, unenjoyable-enjoyable, and bad-good.

Subjective norm was measured using three items (e.g., "People who are important to me would approve of my decision to [pre-drink] over the next four weeks") with responses made on 6-point scales ranging from strongly disagree (1) and strongly agree (6). Perceived behavioural control was measured using three items (e.g., "How much personal control do you have over [pre-drinking] over the next four weeks?") with responses made on six-point scales ranging from no control at all (1), to complete control (6). Intention was measured using three items (e.g., "I intend to pre-drink over the next four weeks") with responses made on 6-point scales anchored by extremely unlikely (1) and extremely likely (6).

Follow-up Pre-drinking Behaviour. In a follow-up questionnaire, participants entered the number of times they had engaged in pre-drinking each week, for the previous four weeks, into four text boxes, using the same CAPI method as in baseline and similar to previous research (e.g., Hagger, Lonsdale, Hein, et al., 2012; LaBrie et al., 2012).

\section{Procedure}


Participants were directed to a web page providing information on the study and a link

2 to the online baseline questionnaire. Participants were informed that consent to participate

3 was considered declared once they indicated that they had agreed with the ethics statements

4 and consented to complete the questionnaire. Participants were required to enter their email

5 address at baseline, which was retained on the server for automated distribution of the

6 invitation to complete the second questionnaire, four weeks later. Participants were either

7 offered prize draw entry or points toward course credit for their participation. Data were

8 matched across time points using an anonymized code unique to each participant.

9 Data Analyses

Variance-based structural equation modeling (VB-SEM) was used to test the adequacy of the hypothesized model in accounting for variance in the endogenous variables while controlling for measurement error and to test for significance of the hypothesized pattern of effects. The analysis was conducted using a non-parametric bootstrap resampling technique with 100 samples to maximize stability of path coefficients (Kock, 2012). All variables in the model were latent variables indicated by their corresponding item(s), including past behaviour, pre-drinking frequency, and demographic variables (age, gender). We controlled for past behaviour, gender, and age in analyses by specifying paths from these variables to each of the other variables in the hypothesized model (e.g., Keatley, Clarke, \& Hagger, 2013b). Table 1 contains descriptive and model evaluation statistics, and zero-order correlations between modelled variables.

Evaluation of the model was made at the measurement and structural levels according to published criteria for VB-SEM models (Vinzi, Chin, Henseler, \& Wang, 2010). In summary, the model is considered suitable if: composite reliability $(\alpha)$ and internal consistency of measures ( $\rho$ ) exceed .70; when average variance explained (AVE) in each 
1 latent variable exceeds .50, and; the AVE for each variable exceeds the value of the

2 correlation between that variable and all others in the model (Vinzi et al., 2010). Full

3 colinearity variance inflation factor (FCVIF) values lower than 3.30 indicate no model issues

4 with multicolinearity (Kock, 2012). Model fit is evaluated by the $Q^{2}$ coefficient exceeding

5 zero for endogenous variables, significant average $R^{2}$ (ARS) and average path coefficient

6 (APC) values (Kock, 2012), and the goodness-of-fit statistic (.10, .25, and .36 correspond to

7 small, medium, and large effect sizes; Tenenhaus, Amato, \& Vinzi, 2004). Hypothesized

8 mediation effects were tested by calculating indirect effects from a bootstrapped resampling

9 method with 100 replications (Kock, 2012). Mediation was confirmed by the presence of a

10 statistically-significant indirect effect, with the direct effect being either statistically

11 significant (partial mediation) or non-significant (full mediation).

\section{Results}

\section{Participants}

A total of $286(83.9 \%)$ of the follow-up sample reported pre-drinking within the previous four weeks, and were included in the final analysis $\left(M_{\text {age }}=21.45\right.$ years $S D=4.35$ years; 94 male, 190 female). The majority (79.2\%) identified as being of Caucasian

17 Australian ethnicity. Descriptive statistics and zero-order latent factor correlations for the 18 study variables are given in Table 1.

\section{Structural Equation Model}

Model evaluation statistics for the measurement and structural levels are included in

21 Table 1. The majority of conditions for model evaluation were satisfied, except for a single

22 indicator of the perceived behavioural control factor, which drastically reduced scale

23 reliability and was removed, and subjective norm factor which was marginally below the .70 
1 criteria for reliability $(\rho=.69)$. All $Q^{2}$ coefficients exceeded zero, indicating sufficient

2 predictive validity in endogenous variables (Kock, 2012). The model predicted $54 \%\left(R^{2}\right.$ Adj $=$

3.53 ) of the variance in student intentions to pre-drink over the next four weeks at baseline, 4 and $20 \%\left(R_{\text {Adj }}^{2}=.18\right)$ of the variance in pre-drinking frequency at follow-up. Fit statistics 5 used to assess VB-SEM models were satisfactory $\left(\mathrm{ARS}=.285 ; \mathrm{ARS}_{\mathrm{Adj}}=.273 ; \mathrm{APC}=\right.$ $6 \quad .168 ; p<.001 ; \mathrm{GoF}=.458)$. Direct effects pertaining to the motivational sequence of the integrated model are depicted in Figure 2. Autonomous motivation was statistically significantly and positively 9 related to attitude and subjective norm, but did not statistically significantly predict perceived behavioural control $(p=.098)$, providing partial support for our hypothesis $\left(\mathrm{H}_{1}\right)$. Contrary to our hypotheses $\left(\mathrm{H}_{2}\right.$ and $\left.\mathrm{H}_{3}\right)$, controlled motivation did not have a statistically significant effect on subjective norm $(p=.118)$, but was statistically significantly and negatively related to attitude and perceived behavioural control. Consistent with the theory of planned behaviour relationships, pre-drinking intention was statistically-significantly predicted by attitude and subjective norm, and negatively predicted by perceived behavioural control, supporting our hypothesis $\left(\mathrm{H}_{4}\right)$. Intention statistically significantly and positively predicted pre-drinking frequency; perceived behavioural control statistically-significantly and negatively predicted pre-drinking behaviour, supporting our hypothesis $\left(\mathrm{H}_{5}\right)$, indicating that participants' perceived behavioural control approximated their actual control over predrinking.

Mediation analyses were conducted by isolating each proposed mediating path and observing the direct, indirect, and total effects and observing whether the mediation was complete (only indirect effect is statistically significant) or partial (both direct and indirect effects are statistically significant) (Kock, 2011). Table 2 lists the hypothesized direct, indirect, and total effects. Broadly consistent with $\mathrm{H}_{6}$, we found statistically significant direct 
1 and indirect effects of autonomous motivation on intention, indicating that this relationship

2 was partially mediated by attitude and subjective norm, but not by, perceived behavioural

3 control $^{3}$. We found no support for the mediating effects of controlled motivation on intentions

4 mediated by subjective norms, leading us to reject our hypothesis $\left(\mathrm{H}_{7}\right)$. There were also no

5 indirect effects of controlled motivation on intention mediated by attitudes and perceived

6 behavioural control in support of our hypothesis $\left(\mathrm{H}_{8}\right)$.

Autonomous motivation had a statistically-significant direct effect on intention (i.e.,

8 the effect was not completely mediated), yet we found no direct effects for controlled

9 motivation on intention, indicating only partial support for our hypothesis $\left(\mathrm{H}_{9}\right)$. We found no

10 support for three-segment paths from autonomous motivation to pre-drinking behaviour,

11 mediated by attitude, subjective norm, perceived behavioural control, and intention, leading

12 us to reject our hypothesis $\left(\mathrm{H}_{10}\right)$. The effect of autonomous motivation on pre-drinking

13 behaviour through perceived behavioural control only was also non-significant, leading us to

14 reject out hypothesis $\left(\mathrm{H}_{11}\right)$. We found no support for mediation of the path from controlled motivation to pre-drinking behaviour through subjective norm and intention, leading us to reject out hypothesis $\left(\mathrm{H}_{12}\right)$. The effects were not observed through attitude and perceived

17 behavioural control and intention, supporting our hypothesis $\left(\mathrm{H}_{13}\right)$. Only the indirect pathway

18 from controlled motivation to behaviour through perceived behavioural control was

19 statistically significant; indicating complete mediation and leading us to reject our hypothesis $20\left(\mathrm{H}_{14}\right)$.

\section{Discussion}

\footnotetext{
${ }^{3}$ We also assessed the relative contribution of each of the variables from self-determination theory and the theory of planned behaviour in predicting pre-drinking intention. Of the significant predictors, autonomous motivation, attitudes, and subjective norm explained $12 \%, 30 \%$, and $7 \%$ of the variance in pre-drinking intention, respectively, providing support for motivational sequence of the model.
} 
The purpose of the present study was to test the effectiveness of an integrated model

2 based on self-determination theory and the theory of planned behaviour in predicting pre-

3 drinking intentions and actual pre-drinking behaviour. Findings supported hypotheses of the

4 proposed model, with notable exceptions that have important ramifications for determining

5 the adequacy of the model and its underlying theoretical bases in the context of pre-drinking.

6 Overall, results indicated that individuals form pre-drinking attitudes and subjective norms

7 that are consistent with autonomous reasons for acting (e.g., valuing benefits, enjoyment),

8 and that these influence intentions to pre-drink. These results are consistent with research by

9 Sheeran et al. (1999), who found attitudinally-controlled intentions tended to be reflective of

10 self-determined motives than normatively-controlled intentions. The effect of autonomous

11 motivation on subjective norm also provides support for Amiot et al. (2013), who found that

12 individuals can be autonomously motivated to comply with social influences in engaging in

13 harmful behaviours. That perceived behavioural control was not predicted by autonomous

14 motivation suggests individuals' perceptions of control are not consistent with autonomous

15 reasons for pre-drinking (i.e., participants may value the benefits of pre-drinking, yet this is

16 unrelated to their perceptions of control).

Our results indicate that exhibiting controlled motivation to engage in pre-drinking

behaviour is related to appraising the behaviour in a negative light and beliefs in a lack of

19 control over pre-drinking. An individual who regulates behaviour through external contingencies (e.g., "I will feel embarrassed if I do not pre-drink"), may form negative attitudes towards pre-drinking behaviour (e.g., "harmful”, "bad") and may feel less control over pre-drinking (e.g., "it is up to me whether or not I pre-drink") over the behaviour.

23 However, the effects of controlled motivation on attitude were small (i.e., $\beta=-.08$ ), 24 compared to those of autonomous motivation on attitude. This is consistent with research showing autonomous motivation tends to be a stronger predictor of intention compared to 
1 controlled motivation (Brickell, Chatzisarantis, \& Pretty, 2006; N. L. Chatzisarantis, Hagger,

2 \& Smith, 2007; Hagger, Lonsdale, Hein, et al., 2011; Sheeran et al., 1999) That controlled

3 motivation exerts a stronger effect on perceived behavioural control suggests pre-drinking

4 may influence control beliefs that have a more substantial direct effect on behaviour, than

5 through intention.

The null effect of controlled motivation on subjective norm and subsequent rejection

7 of this hypothesis is inconsistent with descriptions of subjective norms as representing

8 perceived social approval of engaging in behaviour, characteristic of controlled forms of

9 motivation (Hagger, Lonsdale, Hein, et al., 2012). However, it may be that subjective norms

10 are interpreted as more consistent with autonomous reasons for pre-drinking, rather than

11 controlled. Finally, perceived behavioural control was negatively predicted by controlled motivation. This may mean that engaging in pre-drinking for controlled reasons (e.g., to conform, or avoid guilt) is influential in determining lower personal perceptions of control

14 than determining perceived social approval.

With regards to the mediation effects, the relationship between autonomous motivation and intention was partially mediated through attitude and subjective norm, suggesting that these beliefs are somewhat aligned with overall autonomous motives to engage in pre-drinking, such as fulfilling personally-relevant goals and the perceived social approval of others, supporting our hypotheses regarding these effects. Partial mediation indicates that there may be two processes by which distal motives from self-determination theory affect behaviour: a mediated route that includes intentions and its proximal predictors and a more direct route, that may spontaneously influence intention independent of the

23 formation of belief-based evaluations of pre-drinking (Hagger, Chatzisarantis, \& Harris, 24 2006a). The statistically-significant partial mediation of subjective norm on the autonomous motivation-intention is consistent with Amiot et al.'s (2013) findings and suggests that beliefs 
1 regarding social influences may be more internalized, and, therefore, less likely interpreted as controlling in our sample. This indicates that subjective norm may not constitute self-esteembased rationales for behavioural engagement. intention. Although intention was a statistically-significant predictor of pre-drinking

7 frequency in our model, the effect was small and was indicative of a substantial intention8 behaviour gap (i.e., only $34 \%$ of the variance in behaviour was explained), suggesting the 9 model is not adequate in explaining pre-drinking behaviour. Although this contrasts with the findings of Cooke et al. (2014), their meta-analysis revealed that theory of planned behaviour relationships were moderated by the type of alcohol consumption behaviour, which may be evident in pre-drinking behaviour. Alternatively, Ajzen (2011) states that behaviours that have a considerable intention-behaviour gap may be considered non-reasoned in nature, and current results seem to support the notion that our sample may engage in pre-drinking without forming an explicit intention to do so. This is supported by the fact that some of the social cognitive variables from the model predict behaviour directly independent of intentions, which is a clear sign of less deliberative and more spontaneous effects on behaviour (Hagger, 2013; Hagger \& Chatzisarantis, 2014; Keatley, Clarke, \& Hagger, 2011, 2013a) stronger direct effect of perceived behavioural control on pre-drinking frequency, and lack of support for an indirect effect of perceived behavioural control through intention. It may be that participants who reported higher perceived behavioural control may have not engaged in predrinking over the four weeks from baseline, and, participants with low control over predrinking may have engaged in pre-drinking more frequently over the period between baseline and follow-up. Results indicate that students tend to spontaneously or impulsively engage in pre-drinking when barriers to doing so are removed, as there was no mediation of intention 
1 on the effect of perceived behavioural control on pre-drinking frequency (e.g., Hagger,

2 Anderson, Kyriakaki, \& Darkings, 2007). Given the reported financial hardship experienced

3 by Australian university students (Richard, Bexley, Devline, \& Marginson, 2007) and

4 research indicating the price of alcohol is an important factor determining university students

5 alcohol consumption behaviour (Caudwell \& Hagger, 2014; Miller \& Droste, 2013), it is

6 likely that the cost of drinking or financial situation of students may be a good example of

7 these barriers. Generally speaking, the significant direct effect of past behaviour on pre-

8 drinking frequency suggests substantial variance is unaccounted for by the model variables.

To speculate on the basis of the current data, dual-systems models of behaviour may provide a worthwhile avenue for future research with regards to the prediction of predrinking. Dual systems models posit that behaviour is influenced by reflective and impulsive systems (Perugini, Richetin, \& Zogmaister, 2010; Strack \& Deutsch, 2004). Reflective systems are thought to involve conscious deliberation leading to action (Strack \& Deutsch, 2004); explicit processes which we aim to measure using constructs such as those from the theory of planned behaviour. Conversely, impulsive systems are characterized by perceptual, cue-based influences on behaviour (Strack \& Deutsch, 2004). Researchers using measures of implicit motivational constructs, such as the implicit association test and go/no-go association task, have demonstrated their effectiveness in predicting a range of alcohol consumption outcomes (Caudwell \& Hagger, 2014; Keatley et al., 2013b; Lindgren et al., 2012; Thush \& Wiers, 2007; Wiers et al., 2007). Given the weak intention-behaviour relationship observed in the present study and considerable effect of past behaviour, it is worth ascertaining the influence of constructs from the impulsive system in predicting pre-drinking. Alternatively, the prototype-willingness model (Gibbons \& Gerrard, 1995) incorporates the construct of behavioural willingness (i.e., "how likely are you to engage in behaviour X") alongside the construct of intention. Recent meta-analyses of the effects of prototypes and willingness on 
1 intentions and behaviour in health-related contexts supports the utility of both willingness and

2 intention in predicting behaviour, particularly so in the context of alcohol consumption

3 behaviour (Todd, Kothe, Mullan, \& Monds, 2014; van Lettow, de Vries, Burdorf, \& van

4 Empelen, 2014). A recent "modified" dual-processing approach to the prototype willingness

5 model (Gerrard, Gibbons, Houlihan, Stock, \& Pomery, 2008) suggests some behaviours such

6 as binge drinking may be "neither entirely planful nor entirely impulsive" (Gibbons,

7 Kingsbury, Gerrard, \& Wills, 2011, p. 159), yet still performed with volition (Gerrard et al.,

8 2008). These model developments may therefore provide an alternative framework for future

9 research.

10 The finding that engaging in pre-drinking behaviour is consistent with a sense of self

11 and the satisfaction of psychological needs is a matter of concern, considering pre-drinking

12 alcohol consumption is associated with alcohol-related harm (e.g., Paves, Pedersen, Hummer,

13 \& LaBrie, 2012). This represents a potential conflict in motives and outcomes in that pre-

14 drinking appears to be consistent with autonomous motives and psychological need

15 satisfaction, and therefore likely to be adhered to; whereas some of the outcomes associated

16 with pre-drinking are harmful, and therefore inconsistent with other self-relevant motives

17 such as maintaining good health. Autonomously-motivated pre-drinkers may not be aware of

18 the health risks associated with pre-drinking (e.g., Labhart, Graham, Wells, \& Kuntsche,

19 2013; Reed et al., 2011) or they may not be perceive them to apply to themselves (see Pavey

$20 \&$ Sparks, 2010). Future self-determination theory research should, therefore, focus on

21 behaviours in which individuals may be less likely to pursue positive health goals, such as

22 reducing excessive drinking, because they are in fact autonomously motivated to pursue these

23 health-risk behaviours (e.g., Amiot et al., 2013).

24 Strengths, Limitations, and Avenues for Future Research 

researched behaviour, pre-drinking, which represents a substantive and documented risk to the health of students; (2) the adoption and application of an integrated theoretical model and variance-based structural equation analyses that permitted comprehensive test of the processes by which motivational and belief-based variables impacted on pre-drinking intentions and behaviour; (3) the adoption of a prospective design that allowed the prediction of future pre-drinking behaviour; and (4) the recruitment of a sample of undergraduate students of sufficient size to test hypothesized effects. design was adopted, the current data are correlational and, as with all studies adopting such designs, this places limits on the inference of causality in effects tested in the proposed model (Hagger \& Chatzisarantis, 2009a). In addition, the current sample was not randomly recruited or stratified and this places limits on the generalizability of the findings. However, the distribution and prevalence of pre-drinking activity and overall alcohol consumption of participants in the present study appear broadly consistent with other research (Hummer et al., 2013; LaBrie et al., 2012; Zamboanga et al., 2010) providing some evidence that the current sample's pre-drinking behaviour was characteristic of the target population.

An innovation of the current study is its focus on motivation to engage in pre-drinking behaviour, with findings inconsistent with previous research linking autonomous motivation to the avoidance of risky alcohol consumption (see Neighbors et al., 2007). Given the established links between autonomous motivation and health-promoting behaviours, the finding that autonomous motivation is related to the formation of positive attitudes and intentions to pre-drink presents an issue for self-determination theory research that largely

24 focuses on behaviours and outcomes that are adaptive and conducive to optimal functioning 
1 pre-drinking should seek to resolve this theoretical paradox. This may be by simultaneously

2 examining autonomous and controlled forms of motivation from self-determination theory

3 toward participation in, and avoidance of, pre-drinking. This could potentially assist in

4 helping to resolve the apparent conflict between the motivational factors that underpin

5 approach and avoidance of pre-drinking behaviour.

Theory-based interventions may focus on changing beliefs toward pre-drinking,

7 perhaps by introducing the risk associated with excessive alcohol consumption and pre-

8 drinking or educating students about estimating and employing safe levels of drinking (see

9 De Visser \& Birch, 2012; Pavey \& Sparks, 2010). The key to interventions based on current

10 findings may lie in making health information more salient and promoting autonomous

11 reasons for pursuing healthy choices with respect to alcohol, which may shift attitudes toward

12 reducing excessive drinking in pre-drinkers. However, given the intention-behaviour

13 discrepancy or 'gap' in the present study, there may be little merit in solely attempting to change precursors of behavioural intention if this will not engender behaviour change (Hagger, Lonsdale, \& Chatzisarantis, 2011, 2012; Hagger, Lonsdale, Koka, et al., 2012; Hagger \& Luszczynska, 2013; Webb \& Sheeran, 2006). Research that investigates some of

17 the aspects related to individuals' perceptions of control over pre-drinking (i.e., behavioural 18 barriers) that are unrelated to their intentions may therefore present an important avenue for 19 future research. Furthermore, dual-systems models of behaviour that take into account the measurement of reflective and impulsive determinants of behaviour may allow insights into

21 the factors precipitating pre-drinking (e.g., Caudwell \& Hagger, 2014; Keatley et al., 2011;

22 Keatley et al., 2013b). Inclusion of such measures and may seek to increase the variance

23 accounted for in outcome measures of alcohol consumption, and provide important avenues

24 for theory-based interventions (e.g., Houben, Havermans, Nederkoorn, \& Jansen, 2012; 
In conclusion, the present study identifies some influential motivational and social-

2 cognitive pathways to pre-drinking behaviour that appear somewhat inconsistent with

3 previous research on other alcohol consumption behaviours. Individuals have autonomous

4 motives and strong attitudes toward pre-drinking; and subjective norms seem to be closely

5 aligned with autonomous motives rather than more controlling forms of motivation. Given

6 the prediction of behaviour directly by perceived behavioural control and past behaviour,

7 researchers should consider looking to theories that incorporate impulsive processes that may

8 influence alcohol consumption behaviour beyond intentional or deliberative processes

9 (Hofmann, Friese, \& Wiers, 2011). This study provides a novel contribution to the increasing

10 research focused on pre-drinking as a potentially dangerous pattern of alcohol consumption

11 behaviour common in undergraduate populations. 
References

Ajzen, I. (1991). The theory of planned behavior. Organizational Behavior and Human Decision Processes, 50(2), 179-211. doi: 10.1016/0749-5978(91)90020-t

Ajzen, I. (2002). Constructing a TPB questionnaire: Conceptual and methodological considerations. 1-14.

Ajzen, I. (2014). The theory of planned behaviour is alive and well, and not ready to retire: A commentary on Sniehotta, Presseau, and Araújo-Soares. Health psychology review(Advance online publication), 1-7. doi: 10.1080/17437199.2014.883474

Amiot, C. E., Sansfaçon, S., \& Louis, W. R. (2013). Investigating the motivations underlying harmful social behaviors and the motivational nature of social norms. Journal of Applied Social Psychology, 43(10), 2146-2157. doi: 10.1111/jasp.12167

Armitage, C. J., \& Conner, M. (2001). Efficacy of the theory of planned behaviour: A metaanalytic review. The British Journal of Social Psychology, 40, 471-499.

Brickell, T. A., Chatzisarantis, N. L., \& Pretty, G. M. (2006). Autonomy and Control Augmenting the Validity of the Theory of Planned Behaviour in Predicting Exercise. Journal of Health Psychology, 11(1), 51-63.

Caudwell, K. M., \& Hagger, M. S. (2014). Pre-drinking and alcohol-related harm in undergraduates: the influence of explicit motives and implicit alcohol identity. Journal of Behavioral Medicine, 1-11. doi: 10.1007/s10865-014-9573-6

Chatzisarantis, N. L., Hagger, M. S., \& Smith, B. (2007). Influences of perceived autonomy support on physical activity within the theory of planned behavior. European Journal of Social Psychology, 37(5), 934-954.

Chatzisarantis, N. L. D., Hagger, M. S., Biddle, S. J. H., Smith, B., \& Wang, J. C. K. (2003). A meta-analysis of perceived locus of causality in exercise, sport, and physical education contexts. Journal of Sport and Exercise Psychology, 25(3), 284-306.

Chawla, N., Neighbors, C., Logan, D., Lewis, M. A., \& Fossos, N. (2009). Perceived approval of friends and parents as mediators of the relationship between selfdetermination and drinking. Journal of Studies on Alcohol and Drugs, 70(1), 92.

Conner, M. (2014). Extending not retiring the theory of planned behaviour: a commentary on Sniehotta, Presseau and Araújo-Soares. Health psychology review, 1-5. doi: 10.1080/17437199.2014.899060

Cooke, R., Dahdah, M., Norman, P., \& French, D. P. (2014). How well does the theory of planned behaviour predict alcohol consumption? A systematic review and metaanalysis. Health psychology review(ahead-of-print), 1-20.

De Visser, R. O., \& Birch, J. D. (2012). My cup runneth over: Young people's lack of knowledge of low-risk drinking guidelines. Drug and Alcohol Review, 31(2), 206212. doi: 10.1111/j.1465-3362.2011.00371.x

DeJong, W., DeRicco, B., \& Schneider, S. K. (2010). Pregaming: An exploratory study of strategic drinking by college students in Pennsylvania. Journal of American College Health, 58(4), 307-316. doi: 10.1080/07448480903380300

Del Boca, F. K., \& Darkes, J. (2003). The validity of self-reports of alcohol consumption: State of the science and challenges for research. Addiction, 98, 1-12. doi: 10.1046/j.1359-6357.2003.00586.x

Foster, J. H., \& Ferguson, C. (2013). Alcohol 'pre-loading': A review of the literature. Alcohol and alcoholism, agt135. 
Gerrard, M., Gibbons, F. X., Houlihan, A. E., Stock, M. L., \& Pomery, E. A. (2008). A dualprocess approach to health risk decision making: The prototype willingness model. Developmental Review, 28(1), 29-61. doi: http://dx.doi.org/10.1016/j.dr.2007.10.001

Gibbons, F. X., \& Gerrard, M. (1995). Predicting young adults' health risk behavior. Journal of Personality \& Social Psychology, 69(3), 505-517. doi: 10.1037/00223514.69.3.505

Gibbons, F. X., Kingsbury, J. H., Gerrard, M., \& Wills, T. A. (2011). Two ways of thinking about dual processing: a response to Hofmann, Friese and Wiers (2008). Health psychology review, 5(2), 158-161. doi: 10.1080/17437199.2010.541823

Hagger, M. S. (2009). Theoretical integration in health psychology: Unifying ideas and complementary explanations. British Journal of Health Psychology, 14(2), 189-194. doi: $10.1348 / 135910708 \times 397034$

Hagger, M. S. (2013). The opportunity cost model: Automaticity, individual differences, and self-control resources. Behavioral and Brain Sciences, 36(06), 687-688.

Hagger, M. S., Anderson, M., Kyriakaki, M., \& Darkings, S. (2007). Aspects of identity and their influence on intentional behavior: Comparing effects for three health behaviors. Personality and Individual Differences, 42(2), 355-367. doi: 10.1016/j.paid.2006.07.017

Hagger, M. S., \& Chatzisarantis, N. L. D. (2009a). Assumptions in research in sport and exercise psychology. Psychology of Sport and Exercise, 10(5), 511-519.

Hagger, M. S., \& Chatzisarantis, N. L. D. (2009b). Integrating the theory of planned behaviour and self-determination theory in health behaviour: A meta-analysis. British Journal of Health Psychology, 14(2), 275-302. doi: 10.1348/135910708x373959

Hagger, M. S., \& Chatzisarantis, N. L. D. (2012). Transferring motivation from educational to extramural contexts: a review of the trans-contextual model. European journal of psychology of education, 27(2), 195-212.

Hagger, M. S., \& Chatzisarantis, N. L. D. (2014). An integrated behavior change model for physical activity. Exercise and sport sciences reviews, 42(2), 62-69.

Hagger, M. S., Chatzisarantis, N. L. D., Barkoukis, V., Wang, J. C., Hein, V., Pihu, M., . . Karsai, I. (2007). Cross-cultural generalizability of the theory of planned behavior among young people in a physical activity context. Journal of Sport and Exercise Psychology, 29(1), 1-20.

Hagger, M. S., Chatzisarantis, N. L. D., \& Biddle, S. J. H. (2002). The influence of autonomous and controlling motives on physical activity intentions within the Theory of Planned Behaviour. British Journal of Health Psychology, 7(3), 283-297.

Hagger, M. S., Chatzisarantis, N. L. D., \& Harris, J. (2006a). From psychological need satisfaction to intentional behavior: Testing a motivational sequence in two behavioral contexts. Personality and Social Psychology Bulletin, 32(2), 131-148. doi: $10.1177 / 0146167205279905$

Hagger, M. S., Chatzisarantis, N. L. D., \& Harris, J. (2006b). The process by which relative autonomous motivation affects intentional behavior: comparing effects across dieting and exercise behaviors. Motivation and Emotion, 30(4), 306-320. doi: 10.1007/s11031-006-9046-5

Hagger, M. S., Lonsdale, A., \& Chatzisarantis, N. L. D. (2011). Effectiveness of a brief intervention using mental simulations in reducing alcohol consumption in corporate employees. Psychology, health \& medicine, 16(4), 375-392. doi: 10.1080/13548506.2011.554568

Hagger, M. S., Lonsdale, A., \& Chatzisarantis, N. L. D. (2012). A theory-based intervention to reduce alcohol drinking in excess of guideline limits among undergraduate 
students. British Journal of Health Psychology, 17(1), 18-43. doi: 10.1111/j.20448287.2010.02011.x

Hagger, M. S., Lonsdale, A., Koka, A., Hein, V., Pasi, H., Lintunen, T., \& Chatzisarantis, N. L. D. (2012). An intervention to reduce alcohol consumption in undergraduate students using implementation intentions and mental simulations: A cross-national study. International Journal of Behavioral Medicine, 19(1), 82-96.

Hagger, M. S., Lonsdale, A. J., Hein, V., Koka, A., Lintunen, T., Pasi, H., . . Chatzisarantis, N. L. D. (2011). Predicting alcohol consumption and binge drinking in company employees: An application of planned behaviour and self-determination theories. British Journal of Health Psychology, 1-29. doi: 10.1111/j.2044-8287.2011.02043.x

Hagger, M. S., Lonsdale, A. J., Hein, V., Koka, A., Lintunen, T., Pasi, H., . . Chatzisarantis, N. L. D. (2012). Predicting alcohol consumption and binge drinking in company employees: An application of planned behaviour and self-determination theories. British Journal of Health Psychology, 17(2), 379-407. doi: 10.1111/j.20448287.2011.02043.x

Hagger, M. S., \& Luszczynska, A. (2013). Implementation intention and action planning interventions in health contexts: State of the research and proposals for the way forward. Applied Psychology: Health and Well-Being. doi: 10.1111/aphw.12017

Hallett, J., Howat, P., Maycock, B., McManus, A., Kypri, K., \& Dhaliwal, S. (2012). Undergraduate student drinking and related harms at an Australian university: webbased survey of a large random sample. BMC Public Health, 12(1), 37. doi: 10.1186/1471-2458-12-37

Hofmann, W., Friese, M., \& Wiers, R. W. (2011). Impulsive processes in the self-regulation of health behaviour: Theoretical and methodological considerations in response to commentaries. Health psychology review, 5(2), 162-171. doi: 10.1080/17437199.2011.565593

Houben, K., Havermans, R. C., Nederkoorn, C., \& Jansen, A. (2012). Beer à no-go: learning to stop responding to alcohol cues reduces alcohol intake via reduced affective associations rather than increased response inhibition. Addiction, 107(7), 1280-1287. doi: $10.1111 / \mathrm{j} .1360-0443.2012 .03827 . x$

Houben, K., Nederkoorn, C., Wiers, R. W., \& Jansen, A. (2011). Resisting temptation: Decreasing alcohol-related affect and drinking behavior by training response inhibition. Drug and Alcohol Dependence, 116(1-3), 132-136. doi: 10.1016/j.drugalcdep.2010.12.011

Hummer, J. F., Napper, L. E., Ehret, P. E., \& LaBrie, J. W. (2013). Event-specific risk and ecological factors associated with prepartying among heavier drinking college students. Addictive Behaviors, 38(3), 1620-1628. doi: 10.1016/j.addbeh.2012.09.014

Keatley, D. A., Clarke, D. D., \& Hagger, M. S. (2011). Investigating the predictive validity of implicit and explicit measures of motivation on condom use, physical activity and healthy eating. Psychology \& Health, 27(5), 550-569. doi: 10.1080/08870446.2011.605451

Keatley, D. A., Clarke, D. D., \& Hagger, M. S. (2013a). Investigating the predictive validity of implicit and explicit measures of motivation in problem-solving behavioural tasks. British Journal of Social Psychology, 52(3), 510-524.

Keatley, D. A., Clarke, D. D., \& Hagger, M. S. (2013b). The predictive validity of implicit measures of self-determined motivation across health-related behaviours. British Journal of Health Psychology, 18(1), 2-17. doi: 10.1111/j.2044-8287.2011.02063.x

Knee, C. R., \& Neighbors, C. (2002). Self-determination, perception of peer pressure, and drinking among college students. Journal of Applied Social Psychology, 32(3), 522543. doi: $10.1111 / \mathrm{j} .1559-1816.2002 . t b 00228 . \mathrm{x}$ 
Kock, N. (2011). Using WarpPLS in e-collaboration studies: Mediating effects, control and second order variables, and algorithm choices. International Journal of eCollaboration (IJeC), 7(3), 1-13. doi: 10.4018/jec.2011070101

Kock, N. (2012). WarpPLS 3.0 User Manual (pp. 55). Retrieved from http://www.scriptwarp.com/warppls/UserManual_WarpPLS V3.pdf

Kypri, K., Cronin, M., \& Wright, C. S. (2005). Do univeristy students drink more hazardously than their non-student peers? Addiction, 100(5), 713-714. doi: 10.1111/j.1360-0443.2005.01116.x

Labhart, F., Graham, K., Wells, S., \& Kuntsche, E. (2013). Drinking before going to licensed premises: An event-level analysis of predrinking, alcohol consumption, and adverse outcomes. Alcoholism: Clinical and Experimental Research, 37(2), 284-291. doi: 10.1111/j.1530-0277.2012.01872.x

LaBrie, J. W., Hummer, J. F., Pedersen, E. R., Lac, A., \& Chithambo, T. (2012). Measuring college students' motives behind prepartying drinking: Development and validation of the prepartying motivations inventory. Addictive Behaviors, 37(8), 962-969. doi: 10.1016/j.addbeh.2012.04.003

Lindgren, K. P., Neighbors, C., Teachman, B. A., Wiers, R. W., Westgate, E., \& Greenwald, A. G. (2012). I drink therefore I am: Validating alcohol-related implicit association tests. doi: 10.1016/j.addbeh.2013.01.026

MacLean, S., \& Callinan, S. (2013). "Fourteen Dollars for One Beer!” Pre-drinking is associated with high-risk drinking among Victorian young adults. Australian and New Zealand Journal of Public Health, 37(6), 579-585. doi: 10.1111/1753-6405.12138

McEachan, R. R. C., Conner, M., Taylor, N. J., \& Lawton, R. J. (2011). Prospective prediction of health-related behaviours with the Theory of Planned Behaviour: a meta-analysis. Health psychology review, 5(2), 97-144. doi: $10.1080 / 17437199.2010 .521684$

Miller, P. G., \& Droste, N. (2013). Alcohol price considerations on alcohol and illicit drug use in university students. Journal of Alcoholism and Drug Dependence, 1(109), 2. doi: 10.4172 /jaldd. 1000109

National Health and Medical Research Council. (2009). Australian guidelines to reduce risks from drinking alcohol. Canberra, ACT: Commonwealth of Australia Retrieved from http://www.nhmrc.gov.au/ files nhmrc/publications/attachments/ds10-alcohol.pdf.

Neighbors, C., Larimer, M. E., Markman G., I., \& Knee, C. R. (2004). Feeling controlled and drinking motives among college students: Contingent self-esteem as a mediator. Self and Identity, 3(3), 207-224. doi: 10.1080/13576500444000029

Neighbors, C., Lewis, M. A., Fossos, N., Grossbard, J. R., \& Brown, L. (2007). Motivation and risk behaviors: A self-determination perspective. Psychology of motivation, 99113.

Ng, J. Y. Y., Ntoumanis, M., Thøgersen-Ntoumani, C., Deci, E. L., Ryan, R. M., Duda, J. L., \& Williams, G. C. (2012). Self-determination theory applied to health contexts. Perspectives on Psychological Science, 7(4), 325-340. doi: $10.1177 / 1745691612447309$

Paves, A. P., Pedersen, E. R., Hummer, J. F., \& LaBrie, J. W. (2012). Prevalence, social contexts, and risks for prepartying among ethnically diverse college students. Addictive Behaviors, 37(7), 803-810. doi: 10.1016/j.addbeh.2012.03.003

Pavey, J. L., \& Sparks, P. (2010). Autonomy and reactions to health-risk information. Psychology \& Health, 25(7), 855-872. doi: 10.1080/08870440902929528

Pedersen, E. R., \& LaBrie, J. (2007). Partying before the party: Examining prepartying behavior among college students. Journal of American College Health, 56(3), 237245. doi: 10.3200/JACH.56.3.237-246 
Perugini, M., Richetin, J., \& Zogmaister, C. (2010). Prediction of behavior Handbook of implicit social cognition: Measurement, theory, and applications (Vol. 10, pp. 255278).

Reed, M. B., Clapp, J. D., Weber, M., Trim, R., Lange, J., \& Shillington, A. M. (2011). Predictors of partying prior to bar attendance and subsequent BrAC. Addictive Behaviors, 36(12), 1341-1343. doi: 10.1016/j.addbeh.2011.07.029

Richard, J., Bexley, E., Devline, M., \& Marginson, S. (2007). Australian university student finances 2006: Final report of a national survey of students in public universities (U. o. M. Centre for the Study of Higher Education, Trans.) (pp. 97). Canberra, ACT: Universities Australia.

Ryan, R. M., \& Connell, J. P. (1989). Perceived locus of causality and internalization: Examining reasons for acting in two domains. Journal of Personality \& Social Psychology, 57(5), 749-761. doi: 10.1037/0022-3514.57.5.749

Ryan, R. M., \& Deci, E. L. (2000). Self-determination theory and the facilitation of intrinsic motivation, social development, and well-being. American Psychologist, 55(1), 68-78. doi: 10.1037/0003-066x.55.1.68

Sheeran, P., Norman, P., \& Orbell, S. (1999). Evidence that intentions based on attitudes better predict behaviour than intentions based on subjective norms. European Journal of Social Psychology, 29(2-3), 403-406. doi: 10.1002/(SICI)10990992(199903/05)29:2/3<403::AID-EJSP942>3.0.CO;2-A

Strack, F., \& Deutsch, R. (2004). Reflective and impulsive determinants of social behavior. Personality and Social Psychology Review, 8(3), 220-247. doi: 10.1207/s15327957pspr0803_1

Tenenhaus, M., Amato, S., \& Vinzi, V. E. (2004). A global goodness-of-fit index for PLS structural equation modelling. Paper presented at the XLII SIS Scientific Meeting, 2004, Padova, Italy. .

Thush, C., \& Wiers, R. W. (2007). Explicit and implicit alcohol-related cognitions and the prediction of future drinking in adolescents. Addictive Behaviors, 32(7), 1367-1383. doi: 10.1016/j.addbeh.2006.09.011

Todd, J., Kothe, E., Mullan, B., \& Monds, L. (2014). Reasoned versus reactive prediction of behaviour: a meta-analysis of the prototype willingness model. Health psychology review, 1-24. doi: 10.1080/17437199.2014.922895

van Lettow, B., de Vries, H., Burdorf, A., \& van Empelen, P. (2014). Quantifying the strength of the associations of prototype perceptions with behaviour, behavioural willingness and intentions: a meta-analysis. Health psychology review, (Advance online publication), 1-19. doi: 10.1080/17437199.2014.941997

Vinzi, V. E., Chin, W. W., Henseler, J., \& Wang, H. (2010). Handbook of Partial Least Squares : Concepts, Methods and Applications. New York, USA: Springer.

Webb, T. L., \& Sheeran, P. (2006). Does changing behavioral intentions engender behavior change? A meta-analysis of the experimental evidence. Psychological bulletin, 132(2), 249.

Wells, S., Graham, K., \& Purcell, J. (2009). Policy implications of the widespread practice of 'pre-drinking' or 'pre-gaming' before going to public drinking establishments - Are current prevention strategies backfiring? Addiction, 104(1), 4-9. doi: 10.1111/j.13600443.2008.02393.x

Wiers, R. W., Bartholow, B. D., van den Wildenberg, E., Thush, C., Engels, R. C. M. E., Sher, K. J., . . Stacy, A. W. (2007). Automatic and controlled processes and the development of addictive behaviors in adolescents: a review and a model. Pharmacology Biochemistry and Behavior, 86(2), 263-283. doi: 10.1016/j.pbb.2006.09.021 
Wiggers, J., Tindall, J., Gillham, K., \& Lecathelinais, C. (2012). Targeted regulation of licensed premises in a city entertainment precinct: Impact on assaults, street offences, and emergency department presentations. Injury Prevention, 18(Suppl 1), A46-A47. doi: 10.1136/injuryprev-2012-040580d.29

Zamboanga, B., Schwartz, S., Ham, L., Borsari, B., \& Van Tyne, K. (2010). Alcohol expectancies, pregaming, drinking games, and hazardous alcohol use in a multiethnic sample of college students. Cognitive Therapy and Research, 34(2), 124. doi: 
Table 1.

Descriptive and Model Evaluation Statistics and Zero-order Correlation Matrix for Latent Variables in the Hypothesized Model

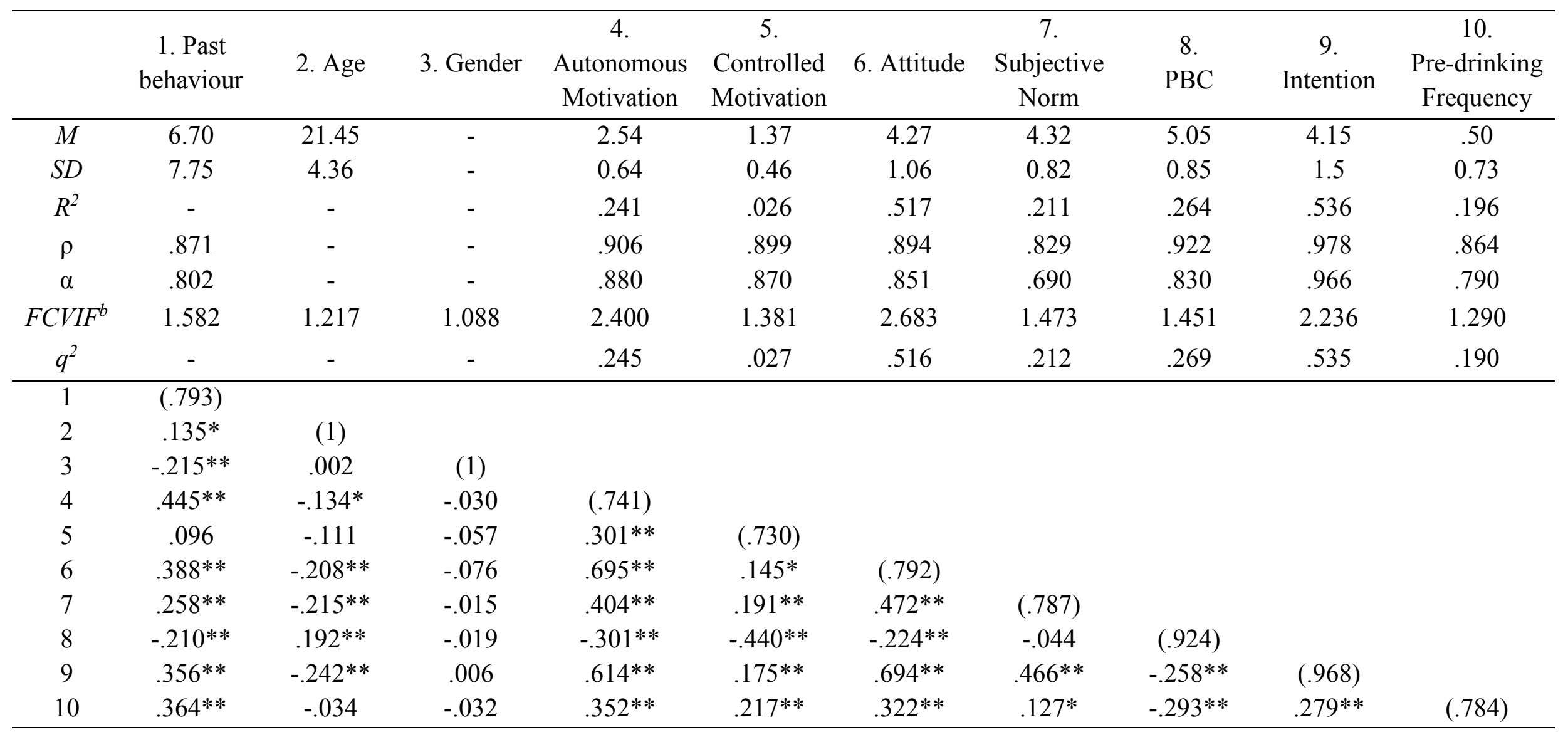

Note. ${ }^{*} \mathrm{p}<.05, * * \mathrm{p}<.01 . \mathrm{PBC}=$ Perceived Behavioural Control; $\rho=$ composite reliability; $\alpha=$ Cronbach's alpha; FCVIF, Full Colinearity Variance Inflation Factor; $q^{2}=$ Qsquared coefficient of predictive utility. The squared average variance extracted (AVE) statistic for each latent variable is presented on the principal diagonal of the correlation matrix. 
Table 2

Mediation Analyses Showing the Direct, Indirect, and Total Effects for the Hypothesized Model Paths

\begin{tabular}{|c|c|c|c|c|c|c|c|c|}
\hline Path & $\operatorname{Direct}\left(f^{2}\right)$ & $p$ & Mediator & Indirect $\left(f^{2}\right)$ & $p$ & Total $\left(f^{2}\right)$ & $p$ & Mediation \\
\hline \multirow{3}{*}{ AM-Int } & \multirow{3}{*}{$.188(.116)$} & \multirow{3}{*}{$<.001$} & Att & $.281(.173)$ & $<.001$ & $.470(.288)$ & $<.001$ & Partial \\
\hline & & & $\mathrm{SN}$ & $.041(.025)$ & .009 & $.229(.141)$ & $<.001$ & Partial \\
\hline & & & $\mathrm{PBC}$ & $.005(.003)$ & .198 & $.194(.119)$ & $<.001$ & None \\
\hline \multirow[t]{2}{*}{ CM-Int } & \multirow[t]{2}{*}{$.015(.003)$} & \multirow[t]{2}{*}{.353} & $\mathrm{SN}$ & $.011(.002)$ & .138 & $.026(.004)$ & .261 & None \\
\hline & & & $\mathrm{PBC}$ & $.030(.005)$ & .058 & $.045(.008)$ & .109 & None \\
\hline \multirow{4}{*}{ AM-PD } & \multirow{4}{*}{$.162(.057)$} & \multirow{4}{*}{.006} & SN-Int & $.002(.001)$ & .310 & $.164(.058)$ & .004 & None \\
\hline & & & PBC-Int & $<.001(<.001)$ & .342 & $.196(.069)$ & .002 & None \\
\hline & & & PBC & $.016(.006)$ & .123 & $.178(.063)$ & .004 & None \\
\hline & & & Int & $.010(.003)$ & .275 & $.172(.060)$ & .001 & None \\
\hline CM-PD & $.102(.022)$ & .064 & Att-Int & $-.005(.001)$ & .121 & $.097(.021)$ & .076 & None \\
\hline
\end{tabular}

Note. $\mathrm{AM}=$ autonomous motivation; $\mathrm{Int}=$ intention; $\mathrm{CM}=$ controlled motivation; $\mathrm{PBC}=$ perceived behavioural control; $\mathrm{PD}=$ pre-drinking frequency; $\mathrm{Att}=\mathrm{Attitude} ; \mathrm{SN}=$ Subjective Norm.

Indirect effects calculated via bootstrap resampling method. Effects are shown controlling for past behaviour, age, and gender. 